\title{
The 'third mission' and 'triple helix mission' of universities as evolutionary processes in the development of the network of knowledge production: Reflections on SME experiences in Thailand
}

\author{
Karantarat Nakwa, National Science and Technology Development Agency, Thailand* \\ Girma Zawdie, University of Strathclyde, $U K^{\star}$
}

\begin{abstract}
This paper explores the 'third mission' and 'triple helix mission' of universities in Thailand in the context of evolutionary processes in the development of the sphere of knowledge production. These functions of universities are often conflated, whereas conceptually they represent separate stages in the evolution of the sphere of knowledge production. The 'third mission' concept is presented in this paper as the antecedent to the 'triple helix mission', and involves relationships between institutional spheres, with the boundaries clearly delineated. In the 'triple helix system', institutional spheres converge and boundaries are blurred. The transition from the 'third mission' to the 'triple helix system' - and the subsequent emergence of entrepreneurial universities - is expedited by the intervention of intermediary organisations that span boundaries and broker between institutional spheres to promote knowledge exchange. Analysis of the experience in Thailand shows that the transition from the 'third mission' to the 'triple helix system' has been constrained by the prevalence of limited networking experience and weak social capital among the triple helix actors, particularly SMEs. This has not been mitigated by consistent policy effort to enhance the effectiveness of the role of intermediaries as boundary spanners and brokers.
\end{abstract}

Keywords: Triple helix; Third mission; entrepreneurial universities; intermediaries; SMEs; knowledge network; Thailand

\section{Introduction}

The wider role of universities as the agency of knowledge production is discussed in contemporary literature in terms of the concepts of 'third mission' and 'triple helix mission' (Pelikan 1992; Gibbons et al. 1994; Brooks 1994; Etzkowitz 1995, 1996; Etzkowitz and Leydesdorff 1995, 2000; Gibb 2001; Zawdie 2010; Dan 2012). The two concepts are related in the sense that both address how universities have historically evolved to assume a new role in which the knowledge they produce impacts the wider economy. In this paper, an attempt is made to locate the 'third mission' of universities as an aspect of the 'triple helix mission'. The

\footnotetext{
* Policy Researcher, National Science and Technology Development Agency, 111 Thailand Science Park, Phahonyothin Road, Khlong Nueng, Khlong Luang, Pathum Thani 12120,Thailand. Email: karantarat@nstda.or.th

- Senior Lecturer, University of Strathclyde, James Weir Building, 75 Montrose Street, Glasgow G1 1XJ, UK. Email: g.zawdie@strath.ac.uk
} 
'third mission' concept represents an incremental development on the teaching and research roles of universities. It is about putting knowledge produced into use with universities reaching out for social and economic players operating outside the boundaries of the sphere of knowledge production. The 'triple helix mission', on the other hand, relates to knowledge production and knowledge use as systemic functions in a dynamically interactive knowledge network and innovation model. As such, the 'third mission' can be conceived as a stage in the evolutionary development of the 'triple helix system'. Cultural barriers, administrative bottlenecks and absence of relevant policy provisions are problems that inhibit the emergence of 'network dynamics' (Nakwa and Zawdie 2015) and hence the transition from the 'third mission' to the 'triple helix mission.

The aim of this paper is to shed some light on what it would take for the 'third mission' of universities in industrially emerging developing countries like Thailand to evolve from simple knowledge networks into a fully-fledged triple helix system. The paper draws on the knowledge network development experience in Thailand with particular reference to the experiences of three SME (small and medium enterprises) clusters. The three SME clusters are drawn from the hard disk drive (HDD) industry; the ceramic industry; and the community-based local textiles industry. The effectiveness of the role of universities with respect to each of these SME clusters is contingent on the characteristics of the markets facing the firms in these clusters and the scope for knowledge absorption and technological capability development of the firms. It also depends on the prevailing policy environment which could either facilitate or constrain network development.

The remainder of this paper is in four parts. The second part of the paper following this introduction looks into the conceptual underpinnings of the 'third mission' and 'triple helix mission' of universities. The third part explores evolution of the sphere of knowledge production in Thailand, including the implications of this for the 'third mission' and 'triple 
helix mission' of universities. The fourth part discusses the data used for exploring the 'third mission' and 'triple helix mission' role of universities in Thailand from the vantage point of SMEs. The fifth part discusses evidence of 'third mission' and 'triple helix mission' activities in Thailand based on the experiences of three SME clusters. The sixth part draws some conclusions.

\section{Third mission vs. triple helix mission of universities}

The engagement of universities in 'third mission' and 'triple helix mission' activities represents a radical departure from their traditional 'ivory tower' stance in which teaching and research were treated as ends in themselves. Universities exist to generate knowledge through teaching and research, but it is also incumbent on them to ensure that the knowledge created is of social and economic value. This gave rise to the awareness that the research and teaching activities of universities would need to be socially and entrepreneurially underpinned through the strategic networking of universities with key players in the wider economy. This awareness has led to the emergence of two concepts - namely, the 'third mission' and the 'triple helix mission'. These concepts together define the trajectory along which universities evolve to impact the economy and the society.

Governments in many countries have sought to ensure that universities are positively engaged in regional and national development programmes through the pursuit of research and development $(R \& D)$ initiatives that lead to innovation, knowledge exchange and knowledge transfer. Both the 'third mission' and the 'triple helix mission' are a response to this policy concern (Zawdie, 2010). It can be argued, however, that the ‘triple helix mission' represents an improvement on the 'third mission', even though the two are part and parcel of the same triple helix-based evolutionary development, albeit at different levels. This view, however, begs the question as to where on the trajectory of evolutionary development the "third 
mission' ceases and the 'triple helix mission' begins. We will explore this conceptually in the following parts of this section.

\subsection{The 'third mission'}

The concept of 'third mission' relates to the evolutionary development of the role of universities. Typically, the 'third mission' can be explained as commercialisation of the teaching and research activities of universities. Laredo (2007), distinguishes between universities in terms of their 'third mission' engagements - i.e. whether they are socially focused, providing services without monetary benefits; or commercially motivated merely by the desire to increase their incomes; or innovation-oriented searching for venture capital to establish spin-off companies and transform their research into business initiatives. Gibbs (2001) argues that these 'third mission' activities constitute the starting point of relationships between universities and external stakeholders in knowledge production.

The 'third mission' evolved from the 'first mission' and 'second mission' of universities. Engagement, solely or predominantly, in teaching constituted the 'first mission' of universities. It took, as Etzkowitz (2008) recounts, the 'first academic revolution' during the $19^{\text {th }}$ century for concern with research to emerge as the 'second mission' of universities. Teaching and research were subsequently found to be synergistic and mutually beneficial; and much in line with Mode 2 proposed by Gibbons et al. (1994), the 'third mission' evolved to make the engagement of universities in teaching and research useful for the wider community. The commitment of universities to 'third mission' initiatives would make them useful places of learning, but not necessarily entrepreneurial as, quite often is the case, they are no more than an 'add-on' to the traditional university activities of teaching and research.

As conceptualization of the innovation process evolved from the linear to the non-linear network model, views about the role of university also changed. The 'third mission' emerged mainly to facilitate technology transfer from universities to stakeholders in knowledge 
production in the wider economy. This was facilitated by the establishment of technology transfer/licensing offices (TTOs/TLOs), which in turn stimulated the growth of 'third mission' activities, such as university spin-offs and start-ups, science parks, incubators, business angels and venture capital. The 'third mission' thus provided a platform for leveraging the transfer of codified knowledge from university to industry and for developing a more complex network system that would allow the broadening and deepening of knowledge exploration and exploitation, and hence the emergence of universities as entrepreneurial players.

\subsection{The 'triple helix mission'}

The emergence of entrepreneurial universities is generally associated with the phenomenon of 'network dynamics' that underpin the development of the 'triple helix system' (Nakwa and Zawdie 2015). The 'triple helix' concept was first proposed by Etzkowitz and Leydesdorff $(1995,2000)$ in the context of the evolutionary theory of innovation (Nelson and Winter, 1974, 1982) to explain the systemic nature of the interaction between universities (engaged in knowledge generation and transfer), industry (engaged in the application/use of knowledge), and government (engaged in the provision of the requisite policy framework for knowledge circulation to thrive). As such, the 'triple helix' concept has been interpreted by Leydesdorff and Zawdie (2010) as a heuristic to unravel the concept of the national innovation system initiated and developed by Freeman (1987) and Lundvall (1992).

The 'triple helix system' involves evolving relationships between the three institutional spheres of knowledge production (university), knowledge use (industry) and policy and governance (government). The relationship between these spheres culminates in the formation of a hybrid system in which the university ultimately acquires entrepreneurial character; enhances its innovation capabilities; and engages in the pursuit of knowledge network development (Etzkowitz and Leydesdorff, 2000). The entrepreneurial university would 
engage in activities that go beyond the 'third mission' to include engagements in a wider exploration and exploitation of knowledge, and the provision of services as hubs for regional economic and social development.

Dan (2012) refers to the 'triple helix mission' as the 'fourth mission' of universities to emphasise the entrepreneurial role of universities in regional development as intermediaries linking external stakeholders in a network system. Gibb (2001) notes the emergence of entrepreneurial universities to be the hallmark of the 'triple helix' model in which universities feature as the main drivers of regional development (as in the 'Fully Integrated Model'); or as leaders in the formation of knowledge network (as in 'University-led Model'); or as agents securing resources from industry for knowledge generation and transfer (as in the 'External Support Model'). Most of the successful universities in developed countries are said to conform to the 'External Support Model'. However, in developing countries, the industrial sector is not strong enough to support universities, so that it is the first and second models that seem to be relevant.

\subsection{Evolution from third mission to triple helix mission}

For the 'third mission' of universities to morph into the 'triple helix mission', the development of knowledge networks through the agency of knowledge intermediaries is crucial (Nakwa \& Zawdie 2015). Knowledge intermediaries are necessary in the transformation of simple and ad hoc inter-firm networks into 'triple helix networks'. These intermediaries can help firms to create 'network dynamics' by stimulating iterative processes in knowledge creation and knowledge conversion - i.e. the processes of socialization, externalization, combination and internalization of knowledge (Nonaka and Takeuchi, 1995). New knowledge created at the end of each cycle of knowledge conversion and circulated across network players, or stakeholders in knowledge production, contributes to the formation of 'network dynamics', which would propel the process of knowledge creation and 
exploitation from cycle to cycle. Without 'network dynamics', the process of knowledge conversion would cease as users of knowledge (firms) find themselves locked into old technology trajectories (Nakwa and Zawdie, 2015). The existence of 'network dynamics' is sustained through the implementation of appropriate technology and innovation policies.

\section{Evidence of third mission and triple helix mission in Thailand}

\subsection{Promotion of third mission in Thai universities}

Most of the universities in Thailand are considered too weak to be effective players in 'third' and 'triple helix' mission activities (Intarakumnerd et al. 2002; Intarakumnerd 2005). The quality of university graduates has yet to improve to catch up with that of graduates elsewhere in Asia. Moreover, it is noted that most of the research and development activities of Thai universities are seldom geared to the needs of industry, suggesting that existing universityindustry linkages would at best involve 'shallow cooperation' (Ibid).

In recent years, there has been a spate of policy initiatives aimed at promoting the engagement of Thai universities in 'third mission' activities. For instance, the Office of the Higher Education Commission (HEC) launched the University Business Incubators Project (UBIP) in 2004 to support universities to establish incubators. The HEC provides funding for promoting the establishment of start-up and spin-off companies through the implementation of business incubation programmes in 'research-active' universities. Incubators provide space, managerial and technical assistance as well as access to seed capital provided by funding agencies and financial institutions. The HEC also supports the establishment of technology licensing offices (TLOs) in universities with adequate R\&D capabilities. By 2013, there were 56 university incubators and 295 start-ups and spin-offs in Thailand (see Table 1). As a strategy for promoting entrepreneurial initiatives, the Government put in place seed funds for providing low interest loans to university students and alumni trained by these incubators to be set up in business with start-up companies. The Government also provided resources 
through the Science Park Promotion Agency (SPPA) for the establishment of regional science parks involving research-active universities.

These government interventions provided the infrastructural support for the development of the 'third mission' of universities. Effectiveness of these interventions has, however, been contingent on the entrepreneurial drive of host universities and the mechanisms they put in place to make use of the science park and incubation facilities. Some universities opted to have their R\&D systems linked to the activities of science parks, incubators and TLOs. This would give them the experience and confidence that would enable them to engage as intermediaries in the development of knowledge networks.

Table 1: Third mission activities in Thai universities

\begin{tabular}{|c|c|c|c|c|c|c|c|}
\hline Activities & 2008 & 2009 & 2010 & 2011 & 2012 & 2013 & 2014 \\
\hline \multicolumn{8}{|l|}{ Incubation } \\
\hline $\begin{array}{l}\text { - Number of Start-ups } \\
\text { and Spin-offs in } \\
\text { incubators }\end{array}$ & 87 & 126 & 131 & 151 & 158 & 295 & 248 \\
\hline \multicolumn{8}{|l|}{ Patenting } \\
\hline $\begin{array}{l}\text { - Number of patent } \\
\text { applications filed }\end{array}$ & 112 & 58 & 96 & 133 & $\mathrm{~N} / \mathrm{A}$ & N/A & N/A \\
\hline $\begin{array}{l}\text { - Number of patents } \\
\text { granted }\end{array}$ & $\mathrm{N} / \mathrm{A}$ & 30 & 38 & $\mathrm{~N} / \mathrm{A}$ & N/A & 44 & 44 \\
\hline \multicolumn{8}{|l|}{ Technology Transfer } \\
\hline $\begin{array}{l}\text { - Number of projects } \\
\text { transferred to local } \\
\text { communities }\end{array}$ & 203 & 237 & 201 & 140 & N/A & N/A & $\mathrm{N} / \mathrm{A}$ \\
\hline $\begin{array}{l}\text { - Number of joint } \\
\text { projects with industry }\end{array}$ & 170 & 190 & 199 & 250 & $\mathrm{~N} / \mathrm{A}$ & $\mathrm{N} / \mathrm{A}$ & $\mathrm{N} / \mathrm{A}$ \\
\hline
\end{tabular}

Source: Annual Report of Office of the Higher Education Commission, 2015

\subsection{Engagement in triple helix mission}

Since 2004, the Thai Government has adopted industrial clusters and the national innovation system (NIS) as the cornerstone of its industrial and science and technology (S\&T) policies 
(Intarakumnerd 2005). To implement these policies, and so respond to the growing challenges of globalisation and competitiveness, several government agencies were charged with the task of forming new 'triple helix' networks and developing and strengthening existing ones (Pananond, 2007). This led to the establishment of new industrial clusters with government departments and specialised institutes operating as intermediaries to manage these clusters. Some clusters gradually developed into innovation networks, jointly creating new products and processes (NSTDA 2008; NESDB 2006).

\section{The data for exploring knowledge networks from SME perspectives}

Three SME clusters were selected for the purpose of exploring the roles of intermediaries as promoters of the 'triple helix mission' of universities. These include clusters relating to the hard disk drive, ceramic and local textile industries. They were selected to show variations in the role of universities across organisationally and characteristically different SME clusters. The aim is to show, using the case study approach, where universities are effective in promoting SME development in the context of the 'triple helix' innovation system.

This study is explorative based on qualitative analysis. Data used for the study are archival and interview-based. The interview-based survey was conducted on semi-structured basis as part of a wider industry study (Nakwa, 2013). Based on review of the archival data, the interviews were aimed to elicit round pictures of networks and the emergence and functionality of triple helix interactions as well as their roles in intermediating network development in the three SME clusters. In all, 12 individuals were interviewed. These were selected through purposive sampling from industry, university and government. Questions asked in the interviews were open-ended and sought to explore the experiences of interviewees in the formation and operation of networks and the roles and contributions of the interviewees and their institutions. Details of both the data from both the archival and 
interview surveys conducted for the study and on which the discussion in Section 5 is based are presented fully in Nakwa (2013).

The data deriving from archival reviews and interviews were employed in the case analysis comparing the three selected industry clusters in terms of where they stand with respect to the development of triple helix networks across the three SME clusters.

\section{Network development experience of SME clusters and the role of universities}

\subsection{The hard disk drive (HDD) cluster}

The Thai Government has assiduously pursued cluster development policy since 2006 to promote the MNC-based HDD industry. The policy provided incentives for the MNCs to involve local SMEs in their supply chains and help them upgrade the quality of their products to the level required by their MNC clients. The policy also brought forth the need for network intermediaries to build trust and promote cooperation between MNCs and SMEs.

As the agencies of knowledge production, universities played an important role as network intermediaries in promoting development of the HDD cluster. The process was, however, initiated by the Government with the creation of the Hard Disk Drive Institute (HDDI) to manage the HDD cluster. The HDDI subsequently established three University/Industry Cooperation Research Centers (U/ICRCs) in three universities to play a brokering role, so that firms, government agencies and researchers can engage in collaborative projects. Also, through a network of nine universities, the U/ICRCs played a boundary spanning role, providing training in design and engineering to SMEs. This would enable SMEs to learn by reverse engineering and develop the capability to engage in the production of machines for use by the HDD makers. Through the U/ICRCs, universities also sought to see that the knowledge they produced was applied across the cluster of SMEs. 
An example of such a network of SMEs, which the government sought to promote in the HDD industry, is 'TH Alliance'. TH Alliance is a pilot project initiated by HDDI involving a network of four local SMEs engaged in the supply of machinery and equipment to an HDD manufacturing multinational company (MNC). Support for TH Alliance was motivated by the aim to exploit the potential backward linkage effects of the HDD industry.

TH Alliance owes its formation to the Institute of Field Robotics (FIBO) in King Mongkut's University of Technology Thonburi (KMUTT), one of the three I/UCRCs, who identified a list of potential local firms with the basic capability to manufacture automotive products. KMUTT provided the list of SMEs to an HDD maker. Four SMEs were subsequently selected to establish $\mathrm{TH}$ Alliance to provide automotive products to a multinational company engaged in HDD manufacturing. Some of the selected SMEs had competitive advantage in manufacturing capability and others in design capability. Each SME in TH Alliance had to invest in machines and resources for production and testing lines in which it had competitive advantage, thus ensuring that its outputs can be effectively integrated into the whole automation production system. These four SMEs brought together their specific contributions to form a joint station at a site near the location of their MNC client, the HDD maker. Then, as a boundary-spanning intermediary, FIBO facilitated knowledge circulation between the MNC and the local SMEs by providing research support to the SMEs constituting TH Alliance. This support afforded the SMEs opportunities for learning by reverse engineering and the acquisition of knowledge that would enable them to replicate some imported machines and develop their technological capabilities in the process. An important outcome of the establishment of TH Alliance is the upgrading of the design capability of the individual SMEs to a degree that would enable them not only to serve their MNC client, but also to learn and accumulate knowledge in the course of their transactions with the MNC. 
As a sponsoring intermediary, the HDDI supported human resource development in the local SMEs. At the same time, FIBO, a boundary-spanning intermediary, provided training and technical assistance to the four SMEs. For example, an SME in TH Alliance had seven engineers trained in design engineering. This enabled the SME to work on joint projects with its MNC client long after leaving TH Alliance. FIBO also assisted in the specification of documents for quality certification that would enable the SMEs to be readily accepted into their client's supply chain. In addition, the HDDI provided financial support for prototype development at TH Alliance on grounds that at the end of the project period, the HDD maker would choose to buy patented machines from TH Alliance.

This triple helix-based arrangement promised short term and long term benefits to the SMEs in TH Alliance. In the short term, working in collusion within TH Alliance qualified SMEs to bid for larger projects tendered by MNCs. The long term benefit was expected to derive in the form of development of local design capability that would enable SMEs to engage - even without government support - in the import substitution of machines to be used by MNCs.

\subsection{The ceramic cluster}

Similar to TH Alliance in the HDD industry, Ceracluster was founded as a cluster company in the ceramic industry based on the cluster development policy and upon guidance and support by a government agency, namely the Ceramic Industries Development Centre (CIDC). Ceracluster was established by twenty SMEs in Lampang province in the northern region of Thailand, where most of the ceramic firms in the country are located.

Local universities had a role to play in the activities of the cluster by providing training services to the SMEs constituting Ceracluster. However, the lead role of these universities in the ceramic cluster was somewhat compromised as they had to operate under the shadow of government agencies, particularly CIDC, which was also involved in the production and circulation of knowledge across firms in Ceracluster. There is no evidence, however, to show 
that local universities were unfairly edged out by CIDC and that university-based research would have served the SME cluster better than that CIDC-based research. In fact, CIDC was better equipped and managed to deliver the required services. For instance, in one particular case, CIDC's R\&D initiative to test the commercial viability of local clay varieties as substitute for imported clays showed local varieties to be too costly to be worthy of commercial consideration.

CIDC also functioned as a broker building cluster networks, mediating among SMEs to build trust and promote interactions between them. It also functioned as a boundary spanner through the provision of training workshops and seminars in collaboration with universities. Together with another government agency, namely Support Arts and Craft International Centre of Thailand (SACICT), CIDC also sponsored a university and a research institute with specialism in ceramic technology to provide technical assistance to ceramic SMEs. The CIDC-sponsored seminars and training programmes helped the SMEs to understand the concept of cluster in terms of trust and mutual benefits arising from networking; to develop a website as a marketing tool; to design products for trade exhibitions; and to grow their sales turnover.

Thus, while CIDC led the triple helix initiative in the cluster, the engagement of universities in triple helix transactions within the cluster remained somewhat peripheral. This weak position of the universities was aggravated by shortfalls in government financial support for promoting the 'third mission' effort of universities. However, the CIDC intervention as intermediary did not bring forth any significant progress in network development either. The network within the cluster remained loose; and the lack of trust among firms impaired the deepening of triple helix relationships in the cluster. Thus, five years after establishment of the ceramic cluster, there was no evidence of dynamic learning and innovation in the cluster. 
Firms in the cluster only engaged in 'shallow' cooperation, such as staging exhibitions and trade fairs and sharing orders.

Moreover, as a top-down initiative, it is not clear whether what Ceracluster had to offer was in keeping with the needs of the firms within the cluster. For instance, Support Arts and Crafts International Centre of Thailand (SACICT) provided technical assistance for some members in Ceracluster. SACICT also offered financial support to Chulalongkorn University (CU) and Metal and Material Technology Centre (MTEC) for their participation as consultants in the provision of technical assistance to the SMEs in Ceracluster. However, it was found that not all SMEs could adopt the technical recommendations of the consultants partly for lack of manpower and financial resources, and partly because technological development did not anyway feature prominently as a matter of business priority in the perception of the SMEs in the cluster.

A salient feature of Ceracluster is that it stood detached from the mainstream of knowledge circulation depriving itself of opportunities for enterprise development as universities did not play any significant role in its activities. As such, the cluster was not essentially knowledgedriven. Rather, it turned on the provision of government support through CIDC in the form of training workshops, seminars and R\&D services. But this support was erratic as CIDC itself was not regularly funded within the annual government budget framework. No wonder, therefore, that by the end of the 5-year plan in 2010, there was no evidence of a 'triple helix' network associated with Ceracluster.

\subsection{The local textiles cluster}

Network development within the local textile industry began in the northern region of Thailand in 2000 when Chiang Mai University (CMU), a leading university in the region, set up a 'cotton and silk' project under its Science and Technology Institute to upgrade the managerial and technological capabilities of community-based enterprises (CBEs) through 
technology transfer and supply chain management schemes. The cotton and silk project was later upgraded to be a Knowledge and Technology Centre (KTC), and has since played a networking role as an agent of technology transfer, knowledge management and technological capability development for textile CBEs in 17 provinces in northern Thailand. The KTC would select from the community of SMEs those SMEs based on traditional knowledge to develop their production sites into local knowledge centres that would cater for the wider community of firms through collaboration with university researchers. The role of university researchers in this case was to combine traditional knowledge and modern/scientific knowledge, thus creating a synergy of new knowledge set to be accessed by SMEs from within and outwith the cluster.

Universities played brokering and boundary-spanning roles in networking firms and facilitating knowledge circulation between them through the establishment of Knowledge and Technology Centres (KTCs). KTCs catered for the networking needs of local textile SME clusters. Universities were not the only agents engaged in the establishment of KTCs. The Toobkeawma Knowledge Centre was established by a CBE, namely Nadao Dyeing and Weaving Enterprises Community, with the aim to cater for the knowledge exchange needs of the community of textile firms in Lampang Province.

The profiles of the three SME clusters discussed in this section are summarised in Table 2. It is apparent from the experiences of the three SME clusters that the existence of effective intermediaries leveraged by government support is crucial for the development of a 'triple helix network system'. The following sub-section will address this point. 
Table 2: Network status, roles and types of dominant intermediaries establishing triple helix networks

\begin{tabular}{|c|c|c|c|c|c|c|c|c|}
\hline & & Availab & lity of interm & diaries & Types 0 & dominant inter & ediaries & \\
\hline SME Cl & sters & Sponsoring & Brokering & Boundary & University & Government- & Market-led & Network status \\
\hline $\begin{array}{l}\text { MNC-based } \\
\text { SMEs }\end{array}$ & $\begin{array}{l}\text { Hard } \\
\text { disk } \\
\text { drive }\end{array}$ & HDDI & $\begin{array}{l}\text { HDDI, } \\
\text { I/UCRCs }\end{array}$ & $\begin{array}{l}\text { I/UCRCs, } \\
\text { Universities }\end{array}$ & $\checkmark$ & & & $\begin{array}{l}\text { Decline and regrouping of triple } \\
\text { helix network after budget cut }\end{array}$ \\
\hline $\begin{array}{l}\text { Market- } \\
\text { based } \\
\text { SMEs }\end{array}$ & Ceramic & MOI & CIDC & $\begin{array}{l}\text { CIDC, RIs, } \\
\text { Universities }\end{array}$ & & $\checkmark$ & $\checkmark$ & $\begin{array}{l}\text { Self-managed triple helix network } \\
\text { after government withdrawal but } \\
\text { shallow cooperation }\end{array}$ \\
\hline $\begin{array}{l}\text { Community } \\
\text { based SMEs }\end{array}$ & $\begin{array}{l}\text { Local } \\
\text { textiles }\end{array}$ & DEQP, TRF & KTC & $\begin{array}{l}\text { CMU, } \\
\text { experts }\end{array}$ & $\checkmark$ & & $\checkmark$ & $\begin{array}{l}\text { Self-managed triple helix network } \\
\text { after budget cut }\end{array}$ \\
\hline
\end{tabular}

MNCs: Multinational corporations; SMEs: Small and medium enterprises; HDDI: Hard Disk Drive Institute; MOI: Ministry of Industry; KTC: Knowledge and technology centre; DEQP: Department of Environmental Quality Promotion; TRF: Thailand Research Fund; CIDC: Ceramic Industries Development Centre; I/UCRCs: Industry/University Cooperation Research

Centre; CMI: Chiang Mai University; RIs: Research Institutes 


\subsection{Discussion}

Examination of the three SME clusters in terms of the iterative modes of knowledge conversion and creation - i.e. socialisation, externalisation, combination and internalisation (Nonaka and Takeuchi, 1995) - shows that although knowledge creation can be seen to have happened in these SME clusters, none of these cases succeeded in creating self-sustaining 'network dynamics' to underpin development of the 'triple helix system' of innovation (Nakwa 2013; Nakwa and Zawdie 2015). The emergence of 'network dynamics' was constrained by shortfalls in human resource development that has implications for the development of R\&D and innovation capabilities; the limited extent of heterogeneity in the knowledge set that is available for combination mainly due to lack of trust among proprietors of knowledge; and the limited role of intermediaries to ensure that interactions among participants across the knowledge network are sustained. Knowledge intermediaries had to rely on government funding, which was erratic and limited to short-term support. In the circumstances, the network development that occurred could sustain only 'shallow cooperation'.

'Network dynamics' emerge in triple helix relationships as opportunities arise for knowledge combination to happen and as actors with heterogeneous knowledge profiles interact. In the case studies discussed, the existing knowledge network was not robust enough to generate the dynamics that would have created opportunities for sustainable innovation. What little evidence there is about the emergence of 'network dynamics' is apparent in the experience of firms in the local textile cluster and the HDD cluster.

In the case of the local textiles cluster, the boundary spanning role of Payap University (PU) was crucial. PU researchers received social research funds from the Thai Commission of Higher Education to study the local knowledge base of business communities in the textile sector. The researchers selected a few community-based enterprises for their study using the 
participatory approach. It was found that these enterprises would develop higher value added products if they had knowledge about the technology of organic dyeing and how it could be applied with the use of local organic fibres. The researchers contacted the Knowledge Technology Centre (KTC) to have access to a local expert from the cluster of communitybased enterprises (CBEs) with the experience of dyeing using organic colours. Following the establishment of a network between university researchers, selected CBEs, the KTC and the local expert, opportunities were created for the tacit knowledge of the local expert to be transferred to selected CBEs and the university researchers through socialisation via seminars, demonstration projects and learning-by-doing initiatives. For this to happen, the local expert and the PU researchers had to stay with the selected CBEs for about a month to ensure that transfer of dyeing and weaving knowledge happened.

The combination mode of knowledge conversion involved PU researchers liaising with researchers in another university to collaborate on an $\mathrm{R} \& \mathrm{D}$ project aimed at developing a fibre mixer to produce paper from plants. However, the developed machine was not internalised as a component of the production system of the selected CBEs, because application of it on industrial scale was aborted consequent upon funding shortfalls. This did not, however, stall the knowledge conversion process; nor did it inhibit PU from engaging in its 'triple helix mission'. After the success in organic colour dyeing with alternative fibres, PU researchers received funding for another project on the application of new fibres to existing products to be conducted in liaison with community-based enterprises (CBEs) in the eastern region. The researchers had to stay with the CBEs to transfer knowledge about new fibres and organic dyeing and, in return, to learn about the existing production methods of CBEs through socialisation.

It turned out that the knowledge needed in this project was beyond the capability of the researchers to deliver. The task of adapting and testing the application of new fibres called for 
cooperation between the SME communities (CBEs) and coordination of different knowledge sources. The consortium of knowledge players introduced the alternative fibre to the SME communities. However, commercial application of the knowledge for producing new fibres could not happen while the SMEs were not keen on the uptake of the knowledge, possibly for lack of trust of what they perceived to be a 'technology push' effort of the researchers. In the event, a good part of the research outcomes remained unutilised.

In the case of the HDD cluster, FIBO, a university-based boundary spanning agency, played a crucial role in knowledge network development. FIBO provided training in engineering science to the four SMEs in the HDD cluster. Through socialisation, the four SMEs learned from the experiences of each other and were able to realise the benefits arising from working together, and so to upgrade the design capability of their engineers. FIBO also helped firms to learn by reverse engineering. FIBO researchers conducted the reverse engineering of imported machines used by an HDD maker and transferred this knowledge and the production blueprints to the four SMEs in TH Alliance. The firms designed their own blueprints and built prototypes. HDDI provided financial support to the SMEs through FIBO to cover some of the costs of prototype development. After building prototypes, firms codified and filed them in the form of patents. This created an opportunity for the SME engineers to upgrade their technological capabilities from basic to intermediate level.

It is apparent from the interaction between FIBO (University), TH Alliance (the HDD cluster company) and HDDI (Government agency) that a triple helix-oriented network was already on the ground. Indeed, the operation of new production lines in $\mathrm{TH}$ Alliance generated product innovation in the form of newly designed machines that were used as substitutes for imported machines. After integrating production lines, TH Alliance produced 10 newly designed machines to supply to the HDD maker. It was found that the HDD maker purchased seven specialised machines patented by TH Alliance. Unfortunately, the lack of trust between 
the TH Alliance and its MNC client and also between the SMEs in the Alliance led to the breakdown of the network system and dissolution of the TH Alliance.

\section{Conclusion}

This paper has addressed the 'third mission' and 'triple helix mission' of universities in Thailand from the vantage point SME development in the country. The picture emerging from the three case studies shows that while some network development and knowledge sharing occurred facilitated by intermediaries, the extent of this has not been adequate to produce dynamic learning that would see the 'third mission' of universities evolve into 'triple helix mission'. The lack of trust among potential network players; the weak role of intermediaries in promoting network development; and the absence of consistent policy support to network development meant that the knowledge network developed was for the most part too shallow to provide a robust basis for triple helix-based innovation.

For all the shortfalls in the development of the 'triple helix mission' of universities in Thailand, the three case studies show some evidence of learning and knowledge exchange. Salient features of the experiences of these three SME clusters clearly show that low-risk activities with short-term visible outcomes (i.e. training and knowledge creation) can be used to build trust before moving to the more comprehensive and complex stages of network development (Ceglie and Dini, 1999).

In order to keep knowledge networks active and evolving, the Thai Government and knowledge intermediaries have key roles to play. In developing countries, in general, development of the 'triple helix system' is government-initiated, and not university-initiated, as in the case of developed countries (Etzkowitz 1995; Gibb 2001).

Knowledge network development should, therefore, be at the heart of government policy and universities should be supported through the provision of funding to lead the 'triple helix' 
innovation process as intermediaries and through engagement in research involving stakeholders from both the private and public sectors of the economy. Where the intermediary role of universities is not adequate, as is often the case in developing countries, it would be imperative for the Government to support intermediary organisations to sponsor network development as brokers and boundary-spanners.

The role of intermediaries in the emergence of the 'triple helix system' in developing countries like Thailand can hardly be over-emphasised in view of the prevalence of social capital deficit arising from lack of trust which impairs network development and knowledge exchange among potential network players, as was observed among firms in the SME clusters. A major role of intermediaries is to establish trust among network players and promote knowledge exchange and knowledge sharing (Yokakul and Zawdie 2010). This would allow networks to evolve as a self-managed system with network players deepening and broadening their interactive relationships to enhance the scope for innovation. Intermediaries would thus need to develop adaptive capability to combine existing knowledge strands into new knowledge categories. They also need to develop the capability to absorb knowledge from outside the network system with the aim to transfer it to a wide range of knowledge users. 'Network dynamics' can be created as intermediaries gain the capability to create new knowledge through the combination of existing heterogeneous knowledge strands, thereby providing the platform for triple helix-based innovation.

Government commitment for funding support offered to intermediaries should be consistent, albeit conditional on the effectiveness of the intermediaries in promoting a combination of different sources of knowledge through innovative multi-cultural and multi-disciplinary schemes. The experiences discussed in this paper suggest that the 'third mission' and 'triple helix mission' of universities in Thailand would be best served when intermediaries, including universities, play entrepreneurial roles to deepen and broaden network development, 
unconstrained by shortfalls in government funding support. It also suggests that the 'third mission' and 'triple helix mission' of universities would need to be driven by careful assessment of the strategic needs of knowledge users. 


\section{References}

Dan, M., 2012. The Third Mission of Universities in the Development Strategy of Vienna City. Informatica Economică , 16(4), pp.49-56.

Etzkowitz, H. (2008). The triple helix: university-industry-government innovation in action.

Etzkowitz, H. \& Leydesdorff, L. (1995). The Triple Helix: University - Industry Government Relations A Laboratory for Knowledge Based Economic Development. EASST Review, 14(1).

Etzkowitz, H. \& Leydesdorff, L. (2000). The dynamics of innovation: from National Systems and "Mode 2" to a Triple Helix of university-industry-government relations. Research Policy, 29(2), 109-123.

Freeman, C. (1987). Technology, policy, and economic performance : lessons from Japan: London; New York : Pinter Publishers.

Gibb, A. (2001). Towards the Entrepreneurial University? Higher Education in Europe, 26, pp.427-436.

Gibbons, M., Limoges, C., Nowotny, H., Schwartzman, S., Scott, P., \& Trow, M. (1994). The New Production of Knowledge: The Dynamics of Science and Research in Contemporary Societies. London: Sage.

Intarakumnerd, P. (2005). Government Mediation and Transformation of Thailand's National Innovation System. Science Technology \& Society, 10(1), pp.87-104. Available at: http://sts.sagepub.com/cgi/doi/10.1177/097172180401000105 [Accessed August 19, 2013].

Intarakumnerd, P., Chairatana, P. \& Tangchitpiboon, T. (2002). National innovation system in less successful developing countries : the case of Thailand. Research Policy, 31, pp.1445-1457

Laredo, P. (2007). Toward a third mission for universities. Paper presented at the UNESCO Workshop for the Regional Scientific Committee for Europe and North America, 5-6 March 2007, Paris.

Lundvall, B.-Å. (1992). National systems of innovation : towards a theory of innovation and interactive learning: London; New York : Pinter.

Nakwa, K. (2013). Innovation Intermediaries and Triple Helix Networks in Developing Countries with Particular Reference to the Case of Thailand. Glasgow: unpublished $\mathrm{PhD}$ thesis, University of Strathclyde.

Nakwa, K. \& Zawdie, G. (2012). The role of innovation intermediaries in promoting the triple helix system in MNC-dominated industries in Thailand: the case of hard disk drive and automotive sectors. International Journal of Technology Management and Sustainable Development, 11(3), 265-283.

Nakwa, K. \& Zawdie, G. (2015). Structural holes, knowledge intermediaries and evolution of triple helix networks in Thailand with reference to the hard disk drive industry in 
Thailand. International Journal of Technology Management \& Sustainable Development, 14(1), pp. 29-47.

Nakwa, K., Zawdie, G. \& Intarakumnerd, P. (2012). Role of Intermediaries in Accelerating the Transformation of Inter-Firm Networks into Triple Helix Networks: A Case Study of SME-based Industries in Thailand. Procedia - Social and Behavioral Sciences, $52(0), 52-61$.

Nelson, R. R. \& Winter, S. G. (1974). Neoclassical vs. Evolutionary Theories of Economic Growth: Critique and Prospectus. The Economic Journal, 84(336), 886-905.

Nelson, R. R. \& Winter, S. G. (1982). An Evolutionary Theory of Economic Change: Belknap Press of Harvard University Press.

NESDB. (2006). Cluster Mapping Project for Upgrading Competitiveness of Manufacturing and Service Sector (Final Report). Bangkok: National Economic and Social Development Board.

Nonaka, I. \& Takeuchi, H. (1995). The knowledge-creating company : how Japanese companies create the dynamics of innovation: New York : Oxford University Press.

NSTDA. (2008). Guidance and Experiences: Development of Sub-sectoral Innovation Network. Bangkok: National Science and Technology Development Agency.

Pananond, P. (2007). The changing dynamics of Thai multinationals after the Asian economic crisis. Journal of International Management, 13(3), 356-375.

Saad, M., Zawdie, G. \& Malairaja, C. (2008). The triple helix strategy for universities in developing countries: the experiences in Malaysia and Algeria. Science and Public Policy, 35, 431-443.

Yokakul, N. \& Zawdie, G. (2010). Innovation network and technological capability development in the Thai SME sector: The case of the Thai dessert industry. International Journal of Technology Management and Sustainable Development, 9(2), 19-36.

Zawdie, G. (2010). Knowledge exchange and the Third Mission of universities: the Triple Helix and the Third Mission - Schumpeter revisited. Industry and Higher Education (Special Issue), 24(3), 151-155.

(Date of acceptance: 07/01/2016) 